\title{
Correction to: A study of the radiological baseline conditions around the planned Sinop (Turkey) nuclear power plant using the mapping method
}

\author{
Hasan Baltas • Cafer Mert Yesilkanat • Erkan Kiris • \\ Murat Sirin
}

Published online: 10 December 2019

(C) Springer Nature Switzerland AG 2019

Correction to: Environ Monit Assess (2019) 191:660 https://doi.org/10.1007/s10661-019-7819-Z

The original version of this article unfortunately contained a mistake.

The Table 1 was published erroneously.

The corrected Table 1 is shown in the next page. The original article has been corrected.

The online version of the original article can be found at https://doi.org/10.1007/s10661-019-7819-z

H. Baltas $(\bowtie) \cdot$ E. Kiris $\cdot$ M. Sirin

Department of Physics, Faculty of Arts and Science, Recep Tayyip Erdoğan University, 53100 Rize, Turkey

e-mail: hasan.baltas@erdogan.edu.tr

C. M. Yesilkanat

Science Teaching Department, Faculty of Education, Artvin Çoruh University, 08000 Artvin, Turkey 
Table 1 Statistical summary of activity levels of radionuclides for each district

\begin{tabular}{|c|c|c|c|c|c|c|c|c|c|c|c|}
\hline & Statistic Summary & $\begin{array}{l}\text { Center } \\
(N=10)\end{array}$ & $\begin{array}{l}\text { Ayanc1k } \\
(N=18)\end{array}$ & $\begin{array}{l}\text { Boyabat } \\
(N=14)\end{array}$ & $\begin{array}{l}\text { Dikmen } \\
(N=7)\end{array}$ & $\begin{array}{l}\text { Duragan } \\
(N=9)\end{array}$ & $\begin{array}{l}\text { Erfelek } \\
(\mathrm{N}=9)\end{array}$ & $\begin{array}{l}\text { Gerze } \\
(N=8)\end{array}$ & $\begin{array}{l}\text { Saraydüzü } \\
(N=6)\end{array}$ & $\begin{array}{l}\text { Türkeli } \\
(\mathrm{N}=7)\end{array}$ & $\begin{array}{l}\text { All Study Area } \\
(N=88)\end{array}$ \\
\hline \multirow{7}{*}{$\begin{array}{l}{ }^{226} \mathrm{Ra}^{-1} \\
\left(\mathrm{~Bq} \mathrm{~kg}^{-1}\right)\end{array}$} & Min. & 3.61 & 8.62 & 6.47 & 12.83 & 13.58 & 7.43 & 10.21 & 7.12 & 9.09 & 3.61 \\
\hline & Max. & 41.07 & 17.94 & 25.21 & 25.37 & 27.63 & 20.77 & 19.02 & 12.62 & 18.46 & 41.07 \\
\hline & Mean & 15.05 & 12.72 & 13.97 & 16.64 & 20.04 & 12.23 & 13.91 & 11.01 & 13.17 & 14.22 \\
\hline & Stand. dev & 10.48 & 2.43 & 5.99 & 4.85 & 5.58 & 4.75 & 2.47 & 1.96 & 4.09 & 5.66 \\
\hline & Median & 12.21 & 12.60 & 14.19 & 17.01 & 17.86 & 9.89 & 13.58 & 11.62 & 11.52 & 13.00 \\
\hline & Skewness & 1.86 & 0.26 & 0.58 & 0.72 & 0.19 & 1.05 & 0.10 & -2.17 & 0.32 & 1.63 \\
\hline & Kurtosis & 4.39 & -0.27 & -0.13 & 1.13 & -2.06 & -0.17 & -2.00 & 5.09 & -2.32 & 2.06 \\
\hline \multirow{7}{*}{$\begin{array}{l}\left.{ }^{232} \mathrm{Th}^{-\mathrm{Bq} \mathrm{kg}^{-1}}\right)\end{array}$} & Min. & 4.55 & 9.30 & 5.29 & 17.56 & 20.39 & 9.24 & 13.30 & 2.45 & 11.94 & 2.45 \\
\hline & Max. & 26.66 & 26.25 & 38.51 & 49.26 & 40.72 & 36.80 & 30.93 & 16.82 & 23.15 & 49.26 \\
\hline & Mean & 17.10 & 17.24 & 19.37 & 24.27 & 27.80 & 17.18 & 18.15 & 12.51 & 16.89 & 18.93 \\
\hline & Stand. dev & 6.09 & 3.69 & 9.43 & 12.25 & 7.42 & 8.25 & 4.00 & 5.63 & 3.86 & 7.78 \\
\hline & Median & 16.87 & 17.65 & 19.00 & 18.19 & 25.52 & 14.81 & 17.56 & 14.96 & 15.27 & 17.55 \\
\hline & Skewness & -0.58 & 0.08 & 0.59 & 1.78 & 0.69 & 1.94 & 0.55 & -1.46 & 0.64 & 1.25 \\
\hline & Kurtosis & 1.28 & 1.83 & 0.14 & 3.05 & -0.83 & 4.39 & -0.62 & 1.42 & -0.37 & 2.85 \\
\hline \multirow{7}{*}{$\begin{array}{l}{ }^{40} \mathrm{~K}^{\left(\mathrm{Bq} \mathrm{kg}^{-1}\right)}\end{array}$} & Min. & 65.40 & 118.50 & 127.00 & 260.70 & 292.30 & 153.10 & 192.20 & 50.60 & 197.50 & 50.60 \\
\hline & Max. & 673.20 & 371.10 & 485.70 & 467.10 & 519.80 & 373.50 & 362.70 & 258.30 & 368.90 & 673.20 \\
\hline & Mean & 240.03 & 267.23 & 285.31 & 334.14 & 394.63 & 255.87 & 275.35 & 181.53 & 261.21 & 278.62 \\
\hline & Stand. dev & 51.92 & 16.43 & 26.24 & 26.70 & 32.84 & 28.15 & 23.22 & 30.29 & 21.69 & 10.94 \\
\hline & Median & 216.20 & 283.95 & 288.45 & 320.30 & 342.30 & 241.90 & 288.70 & 198.60 & 257.00 & 269.90 \\
\hline & Skewness & 2.32 & -0.65 & 0.29 & 1.05 & 0.32 & 0.12 & -0.22 & -1.21 & 0.97 & 0.82 \\
\hline & Kurtosis & 6.57 & -0.46 & -0.25 & 1.56 & -2.23 & -1.51 & -1.99 & 1.52 & 1.65 & 2.01 \\
\hline \multirow{7}{*}{$\begin{array}{l}{ }^{137} \mathrm{Cs}^{-1} \\
\left(\mathrm{~Bq} \mathrm{~kg}^{-1}\right)\end{array}$} & Min. & 2.31 & 1.16 & 1.16 & 4.01 & 1.46 & 1.06 & 0.51 & 0.96 & 0.48 & 0.48 \\
\hline & Max. & 15.60 & 26.00 & 12.83 & 11.19 & 6.95 & 27.92 & 9.83 & 5.19 & 8.68 & 27.92 \\
\hline & Mean & 7.26 & 4.61 & 4.18 & 3.33 & 2.28 & 5.52 & 4.61 & 2.81 & 3.35 & 4.37 \\
\hline & Stand. dev & 4.79 & 6.21 & 4.05 & 3.59 & 1.90 & 8.72 & 2.85 & 1.27 & 2.94 & 4.88 \\
\hline & Median & 7.08 & 2.07 & 1.85 & 1.80 & 1.50 & 1.70 & 3.97 & 2.35 & 1.92 & 2.11 \\
\hline & Skewness & 0.34 & 2.78 & 1.42 & 2.31 & 2.31 & 2.63 & 0.92 & 1.73 & 1.42 & 2.72 \\
\hline & Kurtosis & -0.81 & 8.49 & 0.91 & 5.45 & 5.39 & 7.18 & 0.06 & 2.97 & 0.44 & 9.26 \\
\hline
\end{tabular}

